\title{
Clinical implementation of pre-treatment DPYD genotyping in capecitabine-treated metastatic breast cancer patients
}

\author{
Chara Stavraka $^{1}$ - $\cdot$ Athanasios Pouptsis ${ }^{1} \cdot$ Leroy Okonta $^{1} \cdot$ Karen DeSouza $^{1} \cdot$ Philip Charlton $^{1} \cdot$ Matthaios Kapiris $^{1}$. \\ Anthony Marinaki ${ }^{2} \cdot$ Eleni Karapanagiotou $^{1} \cdot$ Dionysis Papadatos-Pastos ${ }^{1} \cdot$ Janine Mansi $^{1}$
}

Received: 13 January 2019 / Accepted: 21 January 2019 / Published online: 12 February 2019

(C) The Author(s) 2019

\begin{abstract}
Purpose Metastatic breast cancer (mBC) patients with DPYD genetic variants linked to loss of dihydropyrimidine dehydrogenase (DPD) activity are at risk of severe capecitabine-associated toxicities. However, prospective DPYD genotyping has not yet been implemented in routine clinical practice. Following a previous internal review in which two patients underwent lengthy hospitalisations whilst receiving capecitabine, and were subsequently found to be DPD deficient, we initiated routine $D P Y D$ genotyping prior to starting capecitabine. This study evaluates the clinical application of routine $D P Y D$ screening at a large cancer centre in London.

Methods We reviewed medical records for consecutive patients with $\mathrm{mBC}$ who underwent DPYD genotyping before commencing capecitabine between December 2014 and December 2017. Patients were tested for four DPYD variants associated with reduced DPD activity.

Results Sixty-six patients underwent $D P Y D$ testing. Five (8.4\%) patients were found to carry $D P Y D$ genetic polymorphisms associated with reduced DPD activity; of these, two received dose-reduced capecitabine. Of the 61 patients with $D P Y D$ wildtype, 14 (23\%) experienced grade 3 toxicities which involved palmar-plantar erythrodysesthesia (65\%), and gastrointestinal toxicities (35\%); no patient was hospitalised due to toxicity.

Conclusions Prospective DPYD genotyping can be successfully implemented in routine clinical practice and can reduce the risk of severe fluoropyrimidine toxicities.
\end{abstract}

Keywords DPYD genotyping · DPYD screening · Fluoropyrimidines $\cdot$ Toxicities $\cdot$ Metastatic breast cancer $\cdot$ Capecitabine

Janine Mansi

Janine.mansi@gstt.nhs.uk

Chara Stavraka

chara.stavraka@gstt.nhs.uk

Athanasios Pouptsis

th.pouptsis@gmail.com

Leroy Okonta

leroy.okonta@nhs.net

Karen DeSouza

Karen.DeSouza@bsuh.nhs.uk

Philip Charlton

Philip.charlton@nhs.net

Matthaios Kapiris

Matthaios.kapiris@gstt.nhs.uk
Anthony Marinaki

Tony.Marinaki@ viapath.co.uk

Eleni Karapanagiotou

eleni.karapanagiotou@gstt.nhs.uk

Dionysis Papadatos-Pastos

Dionysis.Papadatos-Pastos@uclh.nhs.uk

1 Breast Unit, Guy's and St Thomas' NHS Foundation Trust and King's Biomedical Centre, 4th Floor, Bermondsey Wing, Great Maze Pond, London SE1 9RT, UK

2 Purine Research Laboratory, Viapath, Guy's and St Thomas' NHS Foundation Trust, Westminster Bridge Road, London SE1 7EH, UK 


\section{Introduction}

Breast cancer is the most common malignancy among women accounting for $23 \%$ of new cancer cases and $15 \%$ of cancer-related deaths annually in the world [1]. Capecitabine, an orally administered pro-drug of 5-fluoruracil has a pivotal role in the therapeutic armamentarium for metastatic breast cancer (mBC) usually as monotherapy but also in combination with lapatinib [2]. Fluoropyrimidines are considered to be safe and well tolerated with a side-effect profile that includes diarrhoea, mucositis, palmar-plantar erythrodysesthesia (PPE), bone marrow suppression and nausea. Although the majority of patients receiving fluoropyrimidines experience mild toxicities, usually managed with supportive measures, approximately $10-30 \%$ of patients will develop severe (grade $\geq 3$ ) toxicities which can result in lengthy hospitalisations or death in $0.5-1 \%$ of cases [3-5].

Fluoropyrimidine toxicities have been strongly associated with reduced activity of the enzyme dihydropyrimidine dehydrogenase (DPD), which is the rate-limiting enzyme in the catabolism of fluoropyrimidines [6-9]. DPD catabolises $80 \%$ of 5 -fluoruracil (5-FU), into the non-cytotoxic metabolite 5-fluoro-5,6-dihydrouracil (dHFU) and patients with partial deficiency have 1.5-times increased 5-FU exposure when treated with standard doses [6, 10]. Approximately, 3-5\% of the North American and European population have partial DPD deficiency, whereas complete deficiency is much rarer with a prevalence of $0.01-0.1 \%$ [11-13].

The activity of DPD has been found to be regulated at the genetic, transcriptional (by transcription factors SP1 and AP3) and post-transcriptional level (microRNA 27-a and microRNA 27-b) [14-16]. The most prevalent cause of DPD deficiency though, is the presence of deleterious polymorphisms in its encoding DPYD gene, which have received much interest as predictive biomarkers for fluoropyrimidine-induced toxicities [13, 17-21]. Four $D P Y D$ genetic variants have been established as clinically relevant and associated with severe toxicities: $D P Y D^{*} 2 \mathrm{~A}$ $($ IVS $14+1 \mathrm{G}>\mathrm{A}$, c. $1905+1 \mathrm{G}>\mathrm{A}$, or rs3918290), c.2846A > T (p.D949V or rs67376798), c.1679T > G (rs55886062, DPYD*13, p.I560S), and c. $1236 \mathrm{G}>\mathrm{A}$ (rs56038477, p.E412E, Hap B3) [13, 22-25]. A fifth variant c.1601G > A (p.S534N, DPYD*4, or rs1801158), has been associated with impaired DPD activity [26] but its clinical relevance remains inconclusive [13]. Current evidence suggests that heterozygous carriers of these variants have an average decrease in the DPD activity of approximately $25 \%$ (c.2846A $>$ T, c.1236G > A) and 50\% $\left(D P Y D^{*} 2 \mathrm{~A}, \mathrm{c} .1679 \mathrm{~T}>\mathrm{G}\right)$ [24]. The Clinical Pharmacogenetics Implementation Consortium (CPIC) has issued guidance on appropriate dose reductions in patients harbouring these polymorphisms to prevent severe toxicities [24] Despite growing evidence supporting the significant clinical and financial benefits of routine DPYD genotype screening prior to fluoropyrimidine administration, this is not yet the standard of care [27-32]. The ability to predict and prevent severe capecitabine-associated toxicities is of paramount importance particularly in metastatic breast cancer patients, as a number of alternative treatment options are available. Such toxicities can result in death or pose significant delays to consequent treatment and may even compromise patients' fitness to receive further treatment.

Based on our initial experience with two $\mathrm{mBC}$ patients who were hospitalised and retrospectively found to be DPD deficient, we previously conducted an internal review including 48 patients and found that: (a) none of the other patients who were receiving capecitabine during that time (December 2012 to December 2013) underwent lengthy hospital admission for capecitabine toxicities and (b) the cost of the inpatient stay far outweighed the total cost of testing all those patients for DPD ( $£ 15525$ versus $£ 1575$ based on the cost of the test at that time) [33].

Following this, routine $D P Y D$ screening prior to prescribing capecitabine was initiated at Guy's and St Thomas' NHS Trust (GSTT) in December 2014 using an in-house developed genotyping assay [34]. In this retrospective observational study, we describe our centre's experience and clinically evaluate prospective DPYD genotyping for metastatic breast cancer patients treated with capecitabine. In particular, we evaluated the feasibility of implementing DPYD tests in routine clinical practice, treatment decisions and outcomes based on the pharmacogenetic test results, and its utility in preventing severe toxicities.

\section{Methods}

\section{Prospective DPYD genotyping}

At GSTT routine, DPYD genotype screening was implemented in December 2014 for all $\mathrm{mBC}$ patients who were thought suitable to receive capecitabine. Patients were tested for the following four DPYD genetic variants which are prevalent in the British population and associated with severe capecitabine-associated toxicities: DPYD*2A $(\mathrm{IVS} 14+1 \mathrm{G}>\mathrm{A}$, c. $1905+1 \mathrm{G}>\mathrm{A}$, or rs3918290), c. $2846 \mathrm{~A}>\mathrm{T}$ (p.D949V or rs67376798), c.1679T $>\mathrm{G}$ (rs55886062, DPYD*13, p.I560S) and c.1601G > A (S534N, $D P Y D^{*} 4$, or rs 1801158) $[34,35]$. The pharmacogenetic tests were performed in our institutional laboratory and their prospective nature was determined by comparing the genotyping date with the date of treatment initiation. 


\section{Patient population}

We retrospectively identified metastatic breast cancer patients who were prescribed capecitabine (monotherapy or in combination with lapatinib) between December 2014 and December 2017 at GSTT.

Electronic patient records were reviewed, and information collected on demographic and clinical characteristics including age, gender, ECOG performance status, prescribed treatment regimen, performance of pre-treatment $D P Y D$ genotyping test, DPYD genotype outcome, time of treatment initiation, nature and grade of capecitabine-associated toxicities, dose modifications, reasons for treatment discontinuation and hospitalisation. Toxicities were graded according to the NCI-CTCAE v4.0. The feasibility of the routine application of $D P Y D$ pre-treatment testing in clinical practice was evaluated by assessing the percentage of patients screened for $D Y P D$ when a prescription of capecitabine was given. The turnaround time of the test was also evaluated as well as the presence of associated treatment delays. Patients who did not receive capecitabine due to non $D P Y D$-related reasons were not included in the analysis.

\section{Statistical analysis}

Descriptive statistics were generated to characterise the study cohort in terms of clinicopathological parameters. Categorical outcomes were presented as a frequency and proportion. The SPSS statistical package version 25 (IBM SPSS Inc., USA).

Official approval for the use of retrospective data was granted by Guy's and St Thomas' Clinical Audit Office. Data were handled in accordance with the Declaration of Helsinki and all patients had provided informed consent prior to $D P Y D$ testing.

\section{Results}

Between December 2014 and December 2017, a total of 72 consecutive $\mathrm{mBC}$ patients were considered for capecitabine as a monotherapy or in combination with lapatinib and tested for DPD deficiency. All patients had a pretreatment DPYD test (100\%). Of these 72 patients, $5 \mathrm{did}$ not receive capecitabine due to poor performance status or disease complications, and 1 patient died 6 days after starting cycle 1 due to variceal bleeding. None of these six patients had a $D P Y D$ variant and they were excluded from the analysis. The final analysis was on the remaining 66 patients. Patient characteristics are summarised in Table 1. Five of $66(8 \%)$ were found to be heterozygous variant allele carriers (Table 1) with their pharmacogenomic test results being accompanied by recommendations for dose
Table 1 Patient demographic and clinical characteristics

\begin{tabular}{ll}
\hline Characteristic & Number $(\%), N=66$ \\
\hline Sex & \\
Male & $2(3 \%)$ \\
Female & $64(97 \%)$ \\
Mean age, years & $58(28-85)$ \\
ECOG performance status & \\
0 & $22(33 \%)$ \\
1 & $24(36 \%)$ \\
2 & $9(14 \%)$ \\
3 & $2(3 \%)$ \\
Not specified & $9(14 \%)$ \\
DPYD status & \\
Wild type & $61(92 \%)$ \\
Heterozygous c.1601G $>\mathrm{A}$ & 2 \\
Heterozygous c.2846A $<\mathrm{T}$ & 2 \\
Heterozygous c.1905+1G $>\mathrm{A}$ & 1 \\
Capecitabine received & $63(95 \%)$ \\
Single agent & $49(22 \%)$ \\
Combination with lapatinib & $14(78 \%)$ \\
\hline
\end{tabular}

ECOG Eastern Cooperative Oncology Group Performance Status

modifications as per our institutional guidelines as follows: heterozygous c. $1905+1 \mathrm{G}>$ A for treatment with $50 \%$ dose reduction, heterozygous c. $2846 \mathrm{~A}>\mathrm{T}$ and heterozygous c. $1601 \mathrm{G}>\mathrm{A}$ for treatment with $25 \%$ dose reduction [34]. Three of these patients did not receive capecitabine, and an alternative regimen was prescribed by their treating physician. Treatment outcomes for the DPYD variant carriers are summarised in Table 2 . The other two patients received a $50 \%$ dose reduction of capecitabine during their first cycle of treatment with no complications. The c. $2846 \mathrm{~A}<\mathrm{T}$ variant carrier had a subsequent dose increase to $75 \%$ on cycle 2 which was tolerated very well. Conversely, on increasing the dose for the c. $1905+1 \mathrm{G}>\mathrm{A}$ carrier she developed grade 3 toxicities (PPE, diarrhoea, nausea, neutropaenia) requiring hospitalisation for 10 days and treatment cessation.

Of the 61 patients with a wild-type $D P Y D$ genotype, 14 (23\%) experienced capecitabine-related adverse events $(\mathrm{G}>\underline{3})$ such as PPE and gastrointestinal symptoms including diarrhoea and mucositis (Table 3 ). In two patients, treatment was stopped, however, none of these patients required hospitalisation. A total of 9 patients (15\%) required a dose reduction at the outset of treatment due to comorbidities or poor performance status. There was no death associated with capecitabine treatment in our patient cohort.

The test turnaround time for the DPYD genotyping results was 2-3 working days and did not cause delays in treatment initiation. The cost of the test was $£ 57.56$ per patient. 
Table 2 Treatment outcomes based on pharmacogenomic results for patients carrying DPYD polymorphisms

\begin{tabular}{|c|c|c|c|}
\hline No. & Patient summary & DPYD variant & Treatment outcome \\
\hline 1 & 56F, ECOG PS1 & Heterozygous c. $2846 \mathrm{~A}<\mathrm{T}$ & $\begin{array}{l}\text { Capecitabine not given } \\
\text { Alternative treatment }\end{array}$ \\
\hline 2 & 42F, ECOG PS 2 & Heterozygous c. $1601 \mathrm{G}>\mathrm{A}$ & $\begin{array}{l}\text { Capecitabine not given } \\
\text { Alternative treatment }\end{array}$ \\
\hline 3 & 62F, ECOG PS 1 & Heterozygous c. $1601 \mathrm{G}>\mathrm{A}$ & $\begin{array}{l}\text { Capecitabine not given } \\
\text { Alternative treatment }\end{array}$ \\
\hline 4 & 45F, ECOG PS 0 & Heterozygous c. $1905+1 \mathrm{G}>\mathrm{A}$ & $\begin{array}{l}\text { C1 DR 50\% with no complications, C2 dose increased to } 75 \% \text { : admit- } \\
\text { ted with G3 toxicities (PPE, diarrhoea, nausea, neutropaenia), treat- } \\
\text { ment stopped, and patient recovered }\end{array}$ \\
\hline 5 & 59F, ECOG PS 0 & Heterozygous c. $2846 \mathrm{~A}<\mathrm{T}$ & C1 DR 50\%: no complications. C2 dose increased to $75 \%$ : no toxicities \\
\hline
\end{tabular}

$F$ female, ECOG PS Eastern Cooperative Oncology Group Performance Status, $C$ cycle, $D R$ dose reduction

Table 3 Capecitabine-related toxicities and dose modifications in DPYD wild-type patients

\begin{tabular}{ll}
\hline Toxicity $\geq$ grade 3 & Number $(\%)(N=61)$ \\
\hline Overall toxicity & $14(23 \%)$ \\
Gastrointestinal toxicities & $5(8 \%)$ \\
Palmar-plantar erythrodysesthesia & $9(15 \%)$ \\
Haematological & $0(0 \%)$ \\
Capecitabine-related hospital admissions & $0(0 \%)$ \\
Treatment discontinuation because of & $2(3 \%)$ \\
capecitabine induced adverse events & \\
Capecitabine related deaths & $0(0 \%)$ \\
Dose reduction on treatment outset & \\
$25 \%$ & $6(10 \%)$ \\
$50 \%$ & $3(5 \%)$ \\
\hline
\end{tabular}

\section{Discussion}

In this observational study, we evaluated the feasibility and usefulness of routine prospective DPYD genotyping for the prevention of severe toxicities in $\mathrm{mBC}$ patients treated with capecitabine. Our results show that the implementation of $D P Y D$ screening in clinical practice was feasible and well accepted by clinicians, as every patient who was considered for capecitabine in our institution was successfully screened. The rapid turnaround time and relatively low cost of the test contributed to this, although these factors may vary across different treatment centres globally. This is in keeping with outcomes from large prospective multicentre studies supporting the feasibility and cost-effectiveness of prospective $D P Y D$ genotyping for patients receiving fluoropyrimidinebased treatment across all tumour types [27, 28].

This evaluation is limited by its relatively small sample size. The low number of $D P Y D$ variant carriers precludes a formal evaluation of the effect of DPYD screening on capecitabine-induced toxicities.
Our patients were screened at our in-house facility for four $D P Y D$ variants with an assay that had a combined predictive value of $>99 \%$ and negative predictive value of $80 \%$ [34]. Only two of the five patients identified as carriers of DPYD polymorphisms received a reduced dose of capecitabine; this was $50 \%$ in both patients, but of note was the severe toxicity when the dose was increased by $25 \%$ for one of these patients. The consequence of giving full dose capecitabine, without the knowledge of the DPD deficiency, could have resulted in very severe morbidity or even death.

The patients who did not receive capecitabine carried c. $2846 \mathrm{~A}>\mathrm{T}$ and c. $1601 \mathrm{G}>\mathrm{A}$ polymorphisms, for which a recommendation of $25 \%$ dose reduction is advised. The variability seen in the treatment decisions made by the physicians could reflect uncertainty due to the lack of adequate safety data in the literature at that time. Only recently have large studies emerged evaluating the clinical relevance and providing safety outcomes for commonly screened variants [13, 27, 28, 32]. Although the Clinical Pharmacogenetics Implementation Consortium (CPIC) has issued comprehensive guidance on dose adjustments, there is a need for more real-world safety data to identify the optimal dosing for each genotype [24, 28].

From the patients found to be wild-type DPYD, only $23 \%$ developed grade 3 toxicities which were managed with supportive measures or dose reductions but did not result in hospitalisation. It has been previously reported that patients who do not carry $D P Y D$ variants can still experience severe side effects. This can be due to the sensitivity of the assay, the presence of unrecognised and hence unscreened polymorphisms, or post-transcriptional modifications and variation in other genes influencing fluoropyrimidine drug metabolism [14, 15, 24, 28, 30]. DPD phenotyping testing can predict DPD activity more accurately than DPYD genotyping, however, its cost and lengthy turnaround time make it difficult to implement in clinical practice [36]. Similarly, not all patients carrying deleterious $D P Y D$ variants will experience severe toxicity at standard doses, which may result in 
their undertreatment. Careful dose titration upon an initial dose reduction has been suggested by CPIC to address this issue [24].

Despite the growing amount of evidence favouring the routine implementation of DPYD genotype screening in clinical practice $[27,28,31]$, this remains a subject of debate and controversy. Utilising pharmacogenomics to prevent avoidable toxicities, and death, is of paramount importance for patient care. This has even greater implications for patients with $\mathrm{mBC}$ for whom a plethora of therapeutic options are available. Our study demonstrates that routine implementation of $D P Y D$ genotyping in this patient population is feasible and can guide treatment decisions in a personalised manner.

Data availability The datasets during and/or analysed during the current study are available from the corresponding author on reasonable request.

\section{Compliance with ethical standards}

Conflict of interest The authors declare no conflict of interest.

Ethical approval All procedures performed in studies involving human participants were in accordance with the Ethical Standards of the Institutional and/or National Research Committee and with the $1964 \mathrm{Hel}-$ sinki Declaration and its later amendments or comparable ethical standards. Official approval for the use of retrospective data was granted by Guy's and St Thomas' Clinical Audit Office. This article does not contain any studies with animals performed by any of the authors.

Informed consent It was obtained from all patients who underwent $D P Y D$ genotyping.

Open Access This article is distributed under the terms of the Creative Commons Attribution 4.0 International License (http://creativeco mmons.org/licenses/by/4.0/), which permits unrestricted use, distribution, and reproduction in any medium, provided you give appropriate credit to the original author(s) and the source, provide a link to the Creative Commons license, and indicate if changes were made.

\section{References}

1. Bray F, Ferlay J, Soerjomataram I, Siegel RL, Torre LA, Jemal A (2018) Global cancer statistics 2018: GLOBOCAN estimates of incidence and mortality worldwide for 36 cancers in 185 countries. CA 68(6):394-424. https://doi.org/10.3322/caac.21492

2. Geyer CE, Forster J, Lindquist D, Chan S, Romieu CG, Pienkowski T, Jagiello-Gruszfeld A, Crown J, Chan A, Kaufman B, Skarlos D, Campone M, Davidson N, Berger M, Oliva C, Rubin SD, Stein S, Cameron D (2006) Lapatinib plus capecitabine for HER2-positive advanced breast cancer. N Engl J Med 355(26):2733-2743. https://doi.org/10.1056/NEJMoa064320

3. Hoff PM, Ansari R, Batist G, Cox J, Kocha W, Kuperminc M, Maroun J, Walde D, Weaver C, Harrison E, Burger HU, Osterwalder B, Wong AO, Wong R (2001) Comparison of oral capecitabine versus intravenous fluorouracil plus leucovorin as first-line treatment in 605 patients with metastatic colorectal cancer: results of a randomized phase III study. J Clin Oncol 19(8):2282-2292. https://doi.org/10.1200/jco.2001.19.8.2282

4. Van Cutsem E, Twelves C, Cassidy J, Allman D, Bajetta E, Boyer M, Bugat R, Findlay M, Frings S, Jahn M, McKendrick J, Osterwalder B, Perez-Manga G, Rosso R, Rougier P, Schmiegel WH, Seitz JF, Thompson P, Vieitez JM, Weitzel C, Harper P (2001) Oral capecitabine compared with intravenous fluorouracil plus leucovorin in patients with metastatic colorectal cancer: results of a large phase III study. J Clin Oncol 19(21):4097-4106. https ://doi.org/10.1200/jco.2001.19.21.4097

5. Mikhail SE, Sun JF, Marshall JL (2010) Safety of capecitabine: a review. Expert Opin Drug Saf 9(5):831-841. https://doi. org/10.1517/14740338.2010.511610

6. Diasio RB, Harris BE (1989) Clinical pharmacology of 5-fluorouracil. Clin Pharmacokinet 16(4):215-237. https://doi. org/10.2165/00003088-198916040-00002

7. Longley DB, Harkin DP, Johnston PG (2003) 5-fluorouracil: mechanisms of action and clinical strategies. Nat Rev Cancer 3(5):330-338. https://doi.org/10.1038/nrc1074

8. van Kuilenburg AB, Haasjes J, Richel DJ, Zoetekouw L, Van Lenthe H, De Abreu RA, Maring JG, Vreken P, van Gennip AH (2000) Clinical implications of dihydropyrimidine dehydrogenase (DPD) deficiency in patients with severe 5-fluorouracil-associated toxicity: identification of new mutations in the DPD gene. Clin Cancer Res 6(12):4705-4712

9. Milano G, Etienne MC, Pierrefite V, Barberi-Heyob M, DeporteFety R, Renée N (1999) Dihydropyrimidine dehydrogenase deficiency and fluorouracil-related toxicity. Br J Cancer 79(3-4):627630. https://doi.org/10.1038/sj.bjc.6690098

10. Heggie GD, Sommadossi JP, Cross DS, Huster WJ, Diasio RB (1987) Clinical pharmacokinetics of 5-fluorouracil and its metabolites in plasma, urine, and bile. Cancer Res 47(8):2203-2206

11. Mattison LK, Fourie J, Desmond RA, Modak A, Saif MW, Diasio RB (2006) Increased prevalence of dihydropyrimidine dehydrogenase deficiency in african-americans compared with caucasians. Clin Cancer Res 12:5491-5495

12. Etienne MC, Lagrange JL, Dassonville O, Fleming R, Thyss A, Renee N, Schneider M, Demard F, Milano G (1994) Population study of dihydropyrimidine dehydrogenase in cancer patients. J Clin Oncol 12(11):2248-2253. https://doi.org/10.1200/ jco.1994.12.11.2248

13. Meulendijks D, Henricks LM, Sonke GS, Deenen MJ, Froehlich TK, Amstutz U, Largiader CR, Jennings BA, Marinaki AM, Sanderson JD, Kleibl Z, Kleiblova P, Schwab M, Zanger UM, Palles C, Tomlinson I, Gross E, van Kuilenburg AB, Punt CJ, Koopman M, Beijnen JH, Cats A, Schellens JH (2015) Clinical relevance of DPYD variants c.1679T $>$ G, c.1236G > A/HapB3, and c. $1601 \mathrm{G}>\mathrm{A}$ as predictors of severe fluoropyrimidine-associated toxicity: a systematic review and meta-analysis of individual patient data. Lancet Oncol 16(16):1639-1650. https://doi. org/10.1016/s1470-2045(15)00286-7

14. Amstutz U, Offer SM, Sistonen J, Joerger M, Diasio RB, Largiadèr CR (2015) Polymorphisms in MIR27A associated with early-onset toxicity in fluoropyrimidine-based chemotherapy. Clin Cancer Res 21(9):2038-2044

15. Offer SM, Butterfield GL, Jerde CR, Fossum CC, Wegner NJ, Diasio RB (2014) microRNAs miR-27a and miR-27b directly regulate liver dihydropyrimidine dehydrogenase expression through two conserved binding sites. Mol Cancer Ther 13(3):742-751. https ://doi.org/10.1158/1535-7163.MCT-13-0878

16. Zhang X, Li L, Fourie J, Davie JR, Guarcello V, Diasio RB (2006) The role of Sp1 and Sp3 in the constitutive DPYD gene expression. Biochimica et biophysica acta 1759(5):247-256. https://doi. org/10.1016/j.bbaexp.2006.05.001 
17. Madi A, Fisher D, Maughan TS, Colley JP, Meade AM, Maynard J, Humphreys V, Wasan H, Adams RA, Idziaszczyk S, Harris R, Kaplan RS, Cheadle JP (2018) Pharmacogenetic analyses of 2183 patients with advanced colorectal cancer; potential role for common dihydropyrimidine dehydrogenase variants in toxicity to chemotherapy. Eur J Cancer 102:31-39. https://doi.org/10.1016/j. ejca.2018.07.009

18. Lee AM, Shi Q, Pavey E, Alberts SR, Sargent DJ, Sinicrope FA, Berenberg JL, Goldberg RM, Diasio RB (2014) DPYD variants as predictors of 5-fluorouracil toxicity in adjuvant colon cancer treatment (NCCTG N0147). J Natl Cancer Inst 106 (12). https:// doi.org/10.1093/jnci/dju298

19. Pellicer M, Garcia-Gonzalez X, Garcia MI, Blanco C, GarciaAlfonso P, Robles L, Gravalos C, Rueda D, Martinez J, Pachon V, Longo F, Martinez V, Iglesias I, Salvador S, Sanjurjo M, Lopez-Fernandez LA (2017) Use of exome sequencing to determine the full profile of genetic variants in the fluoropyrimidine pathway in colorectal cancer patients affected by severe toxicity. Pharmacogenomics 18(13):1215-1223. https://doi.org/10.2217/ pgs-2017-0118

20. Deenen MJ, Tol J, Burylo AM, Doodeman VD, de Boer A, Vincent A, Guchelaar HJ, Smits PH, Beijnen JH, Punt CJ, Schellens JH, Cats A (2011) Relationship between single nucleotide polymorphisms and haplotypes in DPYD and toxicity and efficacy of capecitabine in advanced colorectal cancer. Clin Cancer Res 17(10):3455-3468. https://doi.org/10.1158/1078-0432. Ccr-10-2209

21. Rosmarin D, Palles C, Church D, Domingo E, Jones A, Johnstone E, Wang H, Love S, Julier P, Scudder C, Nicholson G, GonzalezNeira A, Martin M, Sargent D, Green E, McLeod H, Zanger UM, Schwab M, Braun M, Seymour M, Thompson L, Lacas B, Boige V, Ribelles N, Afzal S, Enghusen H, Jensen SA, Etienne-Grimaldi MC, Milano G, Wadelius M, Glimelius B, Garmo H, Gusella M, Lecomte T, Laurent-Puig P, Martinez-Balibrea E, Sharma R, Garcia-Foncillas J, Kleibl Z, Morel A, Pignon JP, Midgley R, Kerr D, Tomlinson I (2014) Genetic markers of toxicity from capecitabine and other fluorouracil-based regimens: investigation in the QUASAR2 study, systematic review, and meta-analysis. J Clin Oncol 32(10):1031-1039. https://doi.org/10.1200/jco.2013.51.1857

22. van Kuilenburg AB, Dobritzsch D, Meinsma R, Haasjes J, Waterham HR, Nowaczyk MJ, Maropoulos GD, Hein G, Kalhoff H, Kirk JM, Baaske H, Aukett A, Duley JA, Ward KP, Lindqvist Y, van Gennip AH (2002) Novel disease-causing mutations in the dihydropyrimidine dehydrogenase gene interpreted by analysis of the three-dimensional protein structure. Biochem J 364(Pt 1): $157-163$

23. Vreken P, Van Kuilenburg AB, Meinsma R, Smit GP, Bakker HD, De Abreu RA, van Gennip AH (1996) A point mutation in an invariant splice donor site leads to exon skipping in two unrelated Dutch patients with dihydropyrimidine dehydrogenase deficiency. J Inherit Metab Dis 19(5):645-654

24. Amstutz U, Henricks LM, Offer SM, Barbarino J, Schellens JHM, Swen JJ, Klein TE, McLeod HL, Caudle KE, Diasio RB, Schwab M (2018) Clinical Pharmacogenetics Implementation Consortium (CPIC) guideline for dihydropyrimidine dehydrogenase genotype and fluoropyrimidine dosing: 2017 update. Clin Pharmacol Ther 103(2):210-216. https://doi.org/10.1002/cpt.911

25. Henricks LM, Lunenburg CA, Meulendijks D, Gelderblom H, Cats A, Swen JJ, Schellens JH, Guchelaar HJ (2015) Translating DPYD genotype into DPD phenotype: using the DPYD gene activity score. Pharmacogenomics 16(11):1277-1286. https://doi. org/10.2217/pgs. 15.70

26. Offer SM, Wegner NJ, Fossum C, Wang K, Diasio RB (2013) Phenotypic profiling of DPYD variations relevant to 5-fluorouracil sensitivity using real-time cellular analysis and in vitro measurement of enzyme activity. Cancer Res 73(6):1958-1968. https://doi.org/10.1158/0008-5472.Can-12-3858

27. Deenen MJ, Meulendijks D, Cats A, Sechterberger MK, Severens JL, Boot H, Smits PH, Rosing H, Mandigers CM, Soesan M, Beijnen JH, Schellens JH (2016) Upfront genotyping of DPYD*2A to individualize fluoropyrimidine therapy: a safety and cost analysis. J Clin Oncol 34(3):227-234. https://doi.org/10.1200/ jco.2015.63.1325

28. Henricks LM, Lunenburg C, de Man FM, Meulendijks D, Frederix GWJ, Kienhuis E, Creemers GJ, Baars A, Dezentje VO, Imholz ALT, Jeurissen FJF, Portielje JEA, Jansen RLH, Hamberg P, Ten Tije AJ, Droogendijk HJ, Koopman M, Nieboer P, van de Poel MHW, Mandigers C, Rosing H, Beijnen JH, Werkhoven EV, van Kuilenburg ABP, van Schaik RHN, Mathijssen RHJ, Swen JJ, Gelderblom H, Cats A, Guchelaar HJ, Schellens JHM (2018) DPYD genotype-guided dose individualisation of fluoropyrimidine therapy in patients with cancer: a prospective safety analysis. Lancet Oncol. https://doi.org/10.1016/s1470-2045(18)30686-7

29. Henricks LM, Opdam FL, Beijnen JH, Cats A, Schellens JHM (2017) DPYD genotype-guided dose individualization to improve patient safety of fluoropyrimidine therapy: call for a drug label update. Ann Oncol 28(12):2915-2922. https://doi.org/10.1093/ annonc/mdx411

30. Lunenburg C, Henricks LM, Guchelaar HJ, Swen JJ, Deenen MJ, Schellens JHM, Gelderblom H (2016) Prospective DPYD genotyping to reduce the risk of fluoropyrimidine-induced severe toxicity: ready for prime time. Eur J Cancer 54:40-48. https://doi. org/10.1016/j.ejca.2015.11.008

31. Ruzzo A, Graziano F, Galli F, Galli F, Rulli E, Lonardi S, Ronzoni M, Massidda B, Zagonel V, Pella N, Mucciarini C, Labianca R, Ionta MT, Bagaloni I, Veltri E, Sozzi P, Barni S, Ricci V, Foltran L, Nicolini M, Biondi E, Bramati A, Turci D, Lazzarelli S, Verusio C, Bergamo F, Sobrero A, Frontini L, Menghi M, Magnani M (2017) Dihydropyrimidine dehydrogenase pharmacogenetics for predicting fluoropyrimidine-related toxicity in the randomised, phase III adjuvant TOSCA trial in high-risk colon cancer patients. Br J Cancer 117(9):1269-1277. https://doi.org/10.1038/ bjc. 2017.289

32. Henricks LM, Lunenburg C, de Man FM, Meulendijks D, Frederix GWJ, Kienhuis E, Creemers GJ, Baars A, Dezentje VO, Imholz ALT, Jeurissen FJF, Portielje JEA, Jansen RLH, Hamberg P, Ten Tije AJ, Droogendijk HJ, Koopman M, Nieboer P, van de Poel MHW, Mandigers C, Rosing H, Beijnen JH, van Werkhoven E, van Kuilenburg ABP, van Schaik RHN, Mathijssen RHJ, Swen JJ, Gelderblom H, Cats A, Guchelaar HJ, Schellens JHM (2018) A cost analysis of upfront DPYD genotype-guided dose individualisation in fluoropyrimidine-based anticancer therapy. Eur J Cancer 107:60-67. https://doi.org/10.1016/j.ejca.2018.11.010

33. De Souza K, Papadatos-Pastos D, Karapanagiotou L, Sandri I, Marinaki A, Mansi J (2015) DPYD genotyping as a potential cost-effective predictive biomarker of capecitabine toxicity in breast cancer. Clin Oncol 27(6):e12. https://doi.org/10.1016/j. clon.2015.01.021

34. Loganayagam A, Arenas Hernandez M, Corrigan A, Fairbanks L, Lewis CM, Harper P, Maisey N, Ross P, Sanderson JD, Marinaki AM (2013) Pharmacogenetic variants in the DPYD, TYMS, CDA and MTHFR genes are clinically significant predictors of fluoropyrimidine toxicity. Br J Cancer 108(12):2505-2515. https://doi. org/10.1038/bjc.2013.262

35. Loganayagam A, Arenas-Hernandez M, Fairbanks L, Ross P, Sanderson JD, Marinaki AM (2010) The contribution of deleterious DPYD gene sequence variants to fluoropyrimidine toxicity in British cancer patients. Cancer Chemother Pharmacol 65(2):403406. https://doi.org/10.1007/s00280-009-1147-x 
36. van Staveren MC, Guchelaar HJ, van Kuilenburg AB, Gelderblom H, Maring JG (2013) Evaluation of predictive tests for screening for dihydropyrimidine dehydrogenase deficiency. Pharmacogenomics J 13(5):389-395. https://doi.org/10.1038/tpj.2013.25
Publisher's Note Springer Nature remains neutral with regard to jurisdictional claims in published maps andinstitutional affiliations. 